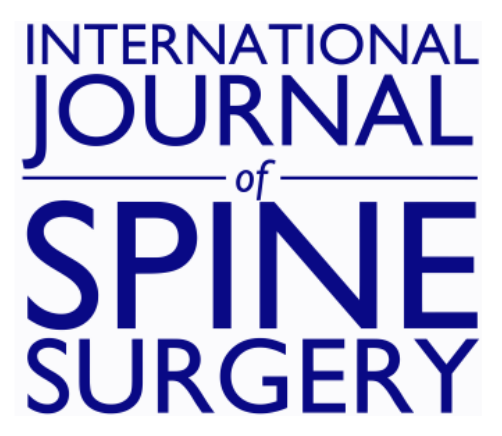

\title{
Myovascular Preserving Open-Door Laminoplasty for Cervical Spondylotic Myelopathy With Miniplate Fixation
}

\author{
YAWARA EGUCHI, MUNETAKA SUZUKI, HAJIME YAMANAKA, HIROSHI TAMAI, \\ TATSUYA KOBAYASHI, SUMIHISA ORITA, MIYAKO NARITA, KAZUHIDE INAGE, \\ HIROHITO KANAMOTO, KOKI ABE, MASAHIRO INOUE, MASAKI NORIMOTO, \\ TOMOTAKA UMIMURA, TAKASHI SATO, YASUCHIKA AOKI, ATSUYA WATANABE, \\ MASAO KODA, TAKEO FURUYA, JUNICHI NAKAMURA, TOMOAKI TOYONE, \\ TOMOYUKI OZAWA, TSUTOMU AKAZAWA, KAZUHISA TAKAHASHI and SEIJI OHTORI
}

Int J Spine Surg 2020, 14 (4) 476-482

doi: https://doi.org/10.14444/7062

http://ijssurgery.com/content/14/4/476

This information is current as of April 26, 2023.

Email Alerts Receive free email-alerts when new articles cite this article. Sign up at: http://ijssurgery.com/alerts 


\title{
Myovascular Preserving Open-Door Laminoplasty for Cervical Spondylotic Myelopathy With Miniplate Fixation
}

\author{
YAWARA EGUCHI, MD, PHD, ${ }^{1,2}$ MUNETAKA SUZUKI, MD, PHD,${ }^{1}$ HAJIME YAMANAKA, MD, PHD, ${ }^{1}$ \\ HIROSHI TAMAI, MD, PHD, ${ }^{1}$ TATSUYA KOBAYASHI, MD, PHD,${ }^{1}$ SUMIHISA ORITA, MD, PHD ${ }^{2}$ \\ MIYAKO NARITA, MD, PHD ${ }^{2}$ KAZUHIDE INAGE, MD, PHD ${ }^{2}$ HIROHITO KANAMOTO, MD, PHD, ${ }^{2}$ \\ KOKI ABE, MD, PHD ${ }^{2}$ MASAHIRO INOUE, MD, PHD,${ }^{2}$ MASAKI NORIMOTO, MD, PHD ${ }^{2}$ \\ TOMOTAKA UMIMURA, MD, PHD,${ }^{2}$ TAKASHI SATO, MD ${ }^{2}$ YASUCHIKA AOKI, MD, PHD, ${ }^{3}$ \\ ATSUYA WATANABE, MD, PHD, ${ }^{3}$ MASAO KODA, MD, PHD,${ }^{4}$ TAKEO FURUYA, MD, PHD ${ }^{2}$ \\ JUNICHI NAKAMURA, MD, PHD, ${ }^{2}$ TOMOAKI TOYONE, MD, PHD, ${ }^{5}$ \\ TOMOYUKI OZAWA, MD, PHD, ${ }^{5}$ TSUTOMU AKAZAWA, MD, PHD, ${ }^{6}$ \\ KAZUHISA TAKAHASHI, MD, PHD, ${ }^{2}$ SEIJI OHTORI, MD, PHD ${ }^{2}$ \\ ${ }^{I}$ Department of Orthopaedic Surgery, Shimoshizu National Hospital, 934-5, Shikawatashi, Yotsukaido, Chiba, Japan, ${ }^{2}$ Department of Orthopaedic Surgery, \\ Graduate School of Medicine, Chiba University, Chiba, Japan, ${ }^{3}$ Department of Orthopaedic Surgery, Eastern Chiba Medical Center, Chiba, Japan, ${ }^{4}$ Department \\ of Orthopedic Surgery, University of Tsukuba, Ibaraki, Japan, ${ }^{5}$ Department of Orthopaedic Surgery, Showa University School of Medicine, Tokyo, Japan, \\ ${ }^{6}$ Department of Orthopaedic Surgery, St. Marianna University School of Medicine, Kanagawa, Japan
}

\begin{abstract}
Objective: Laminoplasty is an effective procedure for treating cervical spondylotic myelopathy. We conduct myovascular preserving open-door laminoplasty (MPLP) in combination with a laminoplasty plate to improve the stability of the enlarged lamina. We compare the details of the MPLP technique with conventional open-door laminoplasty.

Methods: We compared 25 cases of MPLP (mean age $=70.5$, mean follow-up period $=19$ months) with 15 controls who received conventional open-door laminoplasty using hydroxyapatite spacers (mean age $=74$, mean follow-up period $=$ 53 months). Regarding surgical outcomes, blood loss, operative time, Japanese Orthopaedic Association score, and postoperative visual analog score for neck pain were measured. Regarding image analysis, preoperative and postoperative range of motion (ROM), C2-7 angle, implant back out, hinge bone fusion time, presence or absence of hinge bone union failure, and posterior neck fat infiltration rate were evaluated.

Results: Operative time was significantly shorter for MPLP, and postoperative neck pain was significantly decreased. In image evaluation, \% ROM was significantly increased in MPLP, but no difference in C2-7 angle existed between the 2 groups. Implant back out was not recognized in either group. In MPLP, the hinge union period was significantly shortened, and the postoperative fat infiltration rate was significantly decreased.

Conclusions: We were able to reduce neck pain after surgery by an approach entailing longitudinal splitting of the spinous processes. We were able to ensure shorter operation times due to cervical plates and better hinge bone fusion times due to initial stability.

Level of Evidence: 4.
\end{abstract}

Cervical Spine

Keywords: cervical spondylotic myelopathy, open-door laminoplasty, myovascular preservation

\section{INTRODUCTION}

Cervical spondylotic myelopathy (CSM) is a disorder resulting from chronic spinal cord compression due to cervical spondylosis. After the introduction of the laminoplasty by Hirabayashi et $\mathrm{al}^{1}$ in 1977, open-door laminoplasty has become a widely adopted surgical procedure for treating multilevel CSM. Since then, various modifications and procedures have been devised for further improvement of the safety and efficacy of decompression and for stability of the cervical spine.,
We have been using open-door en bloc laminoplasty developed by Itoh and Tsuji ${ }^{3}$ with hydroxyapatite (HA) spacers. This open-door en bloc laminoplasty procedure requires the creation of a hole that allows a thread to be placed through the lateral mass for HA spacer fixation. The lateral mass is occasionally damaged when creating the hole.

Plating is becoming increasingly popular due to the immediate rigid fixation offered. Plates can be used in conjunction with bone struts connected to the plate by screws. ${ }^{4,5}$ 
Table 1. Patient data.

\begin{tabular}{lccc}
\hline Items & MPLP & Control & $\boldsymbol{P}$ Value \\
\hline Age (y) & $70.5 \pm 11.4$ & $74.0 \pm 7.0$ & .43 \\
Male/female & $14 / 11$ & $9 / 6$ & .80 \\
Number of lamina expansion & $2.8 \pm 0.7$ & $2.9 \pm 0.5$ & .68 \\
4 lamina & C3-6: 3 & C3-6: 2 & \\
& C4-7: 1 & & \\
3 lamina & C3-5: 2 & C3-5: 3 & \\
2 lamina & C4-6: 11 & C4-6: 7 & \\
& C4-5: 3 & C5-6: 3 & \\
\hline
\end{tabular}

Abbreviation: MPLP, myovascular preserving open-door laminoplasty.

Recently, spinous process-splitting procedures such as skip laminectomy ${ }^{6-8}$ and myoarchitectonic spinolaminoplasty ${ }^{9}$ have been introduced as less invasive methods sparing the posterior cervical extensor muscles.

From August 2014, we used a unilateral cervical plate to improve the stability of the enlarged lamina. In addition, we performed myovascular preserving open-door laminoplasty (MPLP) to preserve the posterior neck muscle group.

The purpose of this study is to compare clinical and radiological outcomes of the MPLP technique with conventional open-door laminoplasty using HA spacers for CSM.

\section{Materials and Methods}

\section{Subjects}

Informed consent was obtained from all participants before the study began. The study protocol was approved by the ethical review committee.

Among 55 patients who underwent surgery for CSM between November 2012 and May 2018, 40 patients who underwent surgery up until January 2018 were included. For all cases, preoperative and postoperative anterior-posterior and lateral flexionextension views were taken, along with cervical computed tomography (CT) and magnetic resonance imaging (MRI) images. We compared 25 cases of MPLP with miniplate fixation conducted starting in August 2014 with 15 control conventional open-door laminoplasty using HA spacers conducted up until August 2014. In the MPLP group, there were 14 males and 11 females; the mean age was 70.5 (range $=37-85)$; the mean follow-up period was 19 months (range $=8-42$ ); and the mean number of laminoplasties was 2.8. In the control group, there were 9 males and 6 females; the mean age was 74 (range $=62-85$ ); the mean follow-up period was 53 months (range $=48-58$ ); and the mean number of laminoplasties was 2.9. There was no significant difference between the 2 groups (Table 1).

Surgical Technique for MPLP With Miniplate Fixation (Figure 1). Patients are positioned prone and their heads are secured using Mayfield clamps. A linear incision is made in the midline, dorsal to the spinous processes of C3-6 or C4-6. The layers of the nuchal ligaments are cut in the midline. The midline tips of the spinous processes are exposed with the muscles attached on both sides. The spinous processes are cut in the midline using a 2$\mathrm{mm}$ diamond tipped drill until the transition between the lamina and the spinous process and the cortical bone of the spinous processes at the spinolaminar junction is cut laterally and separated at the spinolaminar junction with muscles attached. The surface of the lateral part of the lamina is exposed by retracting the split spinous process together with the attached semispinalis cervicis and multifidus muscles. The lateral gutters are drilled on the lamina on a line just medial to the facet joints. The side with more symptoms is designated as the open side. On the open side, the laminae are completely cut. Then an incomplete fracture hinge is made by removing dorsal cortex and the cancellous bone on the other side. The laminae are carefully opened and an appropriately sized laminoplasty miniplate (Centerpiece Plate Fixation System; Medtronic Sofamor Danek, City, STMemphis, TN, USA) is chosen. The miniplate skips the expanded lamina: it is installed medial or caudal. In the case of C4-6 laminoplasty, the plate is fixed to the C5 lamina, and in the case of C3-6 laminoplasty, plates are fixed to the $\mathrm{C} 4$ and $\mathrm{C} 6$ lamina. The miniplate is anchored to the opened lamina by $25-\mathrm{mm}$ miniscrews and anchored to the lateral mass by 25 -mm miniscrews.

Surgical Technique for Conventional Open-Door Laminoplasty Using HA Spacers. We performed the procedure according to the method of Itoh and Tsuji. ${ }^{3}$ The laminae and intervertebral facets between $\mathrm{C} 3$ and $\mathrm{C} 6$ are exposed by removing all the muscles from those spinous processes and laminae. Each spinous process is carefully removed. Two gutters are made bilaterally in the laminae just medial to each articular process using an air drill. The depth of the gutters is limited to the inner cortex of each lamina. The tunnels for wire passage are made within the laminae using an awl and 

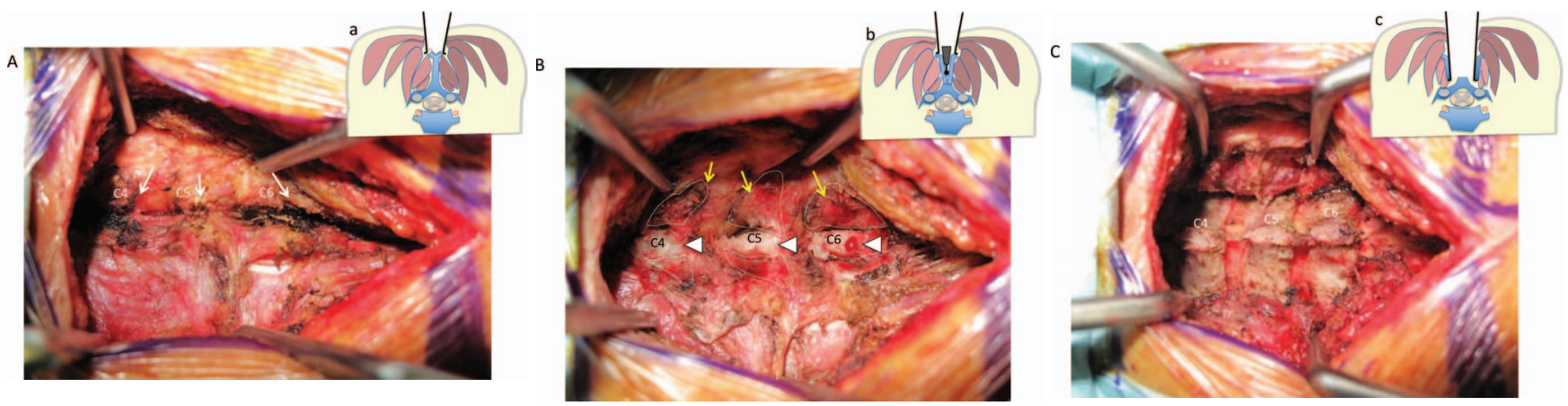

D
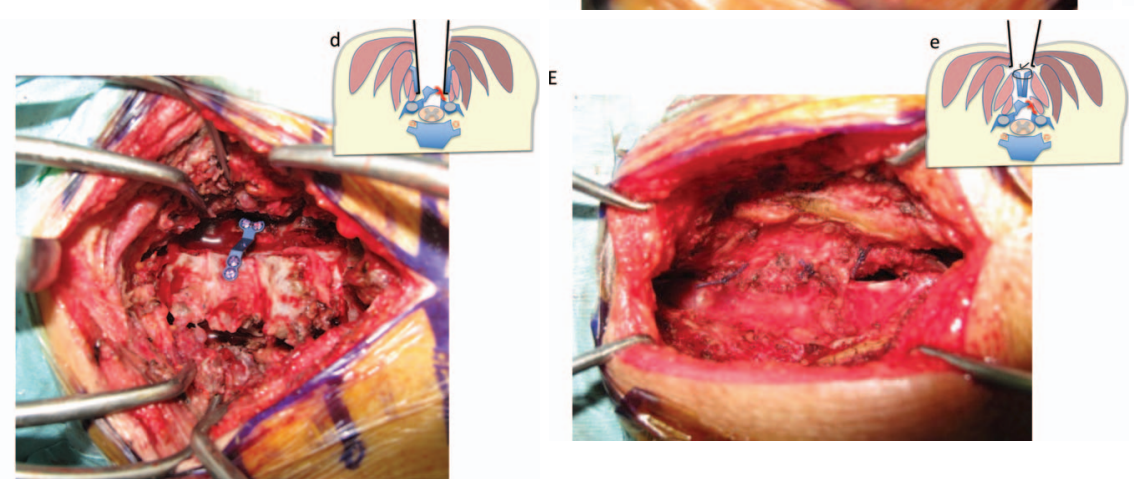

Figure 1. Intraoperative photographs $(A)-(E)$ and cross-section schematic representation (a)-(e) of myovascular preserving open-door laminoplasty. (A), (a) Retracting the apex of the spinous processes; arrow: spinous process tips at C4, C5, and C6. (B), (b) The spinous process is cut longitudinally by a 2-mm diamond shaped drill, the spinous processes are removed at the spinolaminar junction and retracted bilaterally with the muscles attached; arrow: cortical bone of the spinous processes; arrowhead: cross-section of the base of the spinous processes. (C), (c) The surface of the lateral part of the lamina is exposed by retracting of the split spinous process together with the attached semispinalis cervicis and multifidus muscles. (D), (d) The miniplate is anchored to the opened lamina by 2 5-mm miniscrews and anchored to the lateral mass by $25-\mathrm{mm}$ miniscrews. (E), (e) The spinous process with muscles attached is reconstructed by suturing.

pusher and within the inferior articular processes by using a bone perforator in the open side. On the open side, each inner lamina cortex is cut completely. After the edge of the divided lamina is elevated like an open door, the wire is threaded through the lamina with an HA spacer (Apaceram, Pentax,Inc. Tokyo, Japan); the articular process, the HA spacer, and the lamina are fixed by tightening the wires.

Surgical Outcomes. We evaluated intraoperative parameters such as blood loss $(\mathrm{mL})$ and operative time (minutes). The preoperative and postoperative Japanese Orthopaedic Association (JOA; 0-17 points) scores were used to assess neurological function. A visual analog score (VAS) ranging from $0 \mathrm{~mm}$ (no pain) to $100 \mathrm{~mm}$ (extreme amount of pain) was used to evaluate the severity of postoperative neck pain.

Image Analysis. We performed radiographic analyses before and at 6 months after surgery. C2-7 angle refers to the angle between the line vertical to the inferior aspect of the $\mathrm{C} 2$ body and the line vertical to that of the $\mathrm{C} 7$ body on a neutral lateral radiograph. Preoperative and postoperative range of motion (ROM) was measured as the difference between the $\mathrm{C} 2-7$ angle on lateral flexion and extension radiographs of the cervical spine. The percent of cervical ROM was calculated in each patient using the following formula: $\% \mathrm{ROM}=$ (postoperative ROM/preoperative ROM) $\times 100$. Whether 29 plates and 17 spacers used were displaced, mean time until hinge bone fusion (in months) and whether failure of union for hinge bone had occurred were evaluated using CT images at $1,3,6,9,12$, and 18 months after the surgery. For time to hinge bone fusion, we evaluated bone union on the hinge side of the lamina where the implant was installed (23 MPLP vertebrae, 8 control vertebrae). Failure of hinge bone union was evaluated by examining the hinge side of the enlarged vertebrae (64 MPLP laminae, 44 control laminae). The posterior cervical muscle fat infiltration (FI) rate was calculated for each patient with cross-sectional areas of axial CT taken parallel to the C5 intervertebral level using software (AZE Virtual Place, Fujin Raijin 340 3.4003, AZE Ltd., Tokyo, Japan) before and at 6 months after surgery. CT was used to measure the FI rate $(\%)$ of the paraspinal muscles in the lumbopelvic spine. ${ }^{10,11}$ 


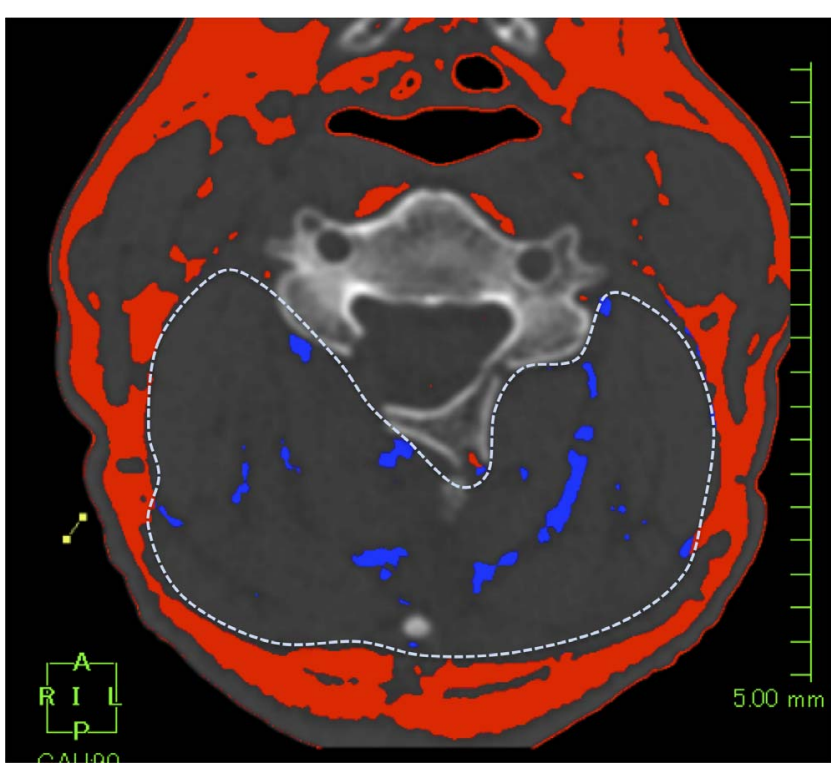

Figure 2. Analysis of posterior cervical muscle fat infiltration rate. Cervical cross-section computed tomography images were analyzed using AZE VirtualPlace. Fat in the posterior cervical muscles is labeled in blue. Posterior cervical muscle fat infiltration proportion $(\%)=$ (cross-sectional area of posterior cervical intramuscular fat [blue]/cross-sectional area of posterior neck muscle [dotted line]) $\times 100$.

The FI rate was measured using muscle attenuation via the Hounsfield unit (HU); FI = area with fatspecific $\mathrm{HU} /$ whole back muscle area with varied HU. Posterior cervical muscle FI rate $\%=$ (crosssectional area of posterior cervical muscle fat [blue]/ posterior neck muscle [dotted line] $) \times 100$ (Figure 2).

Statistical Analysis. Statistical analyses were performed with Stat View software (version 5.0). Differences between the MPLP group and control group were evaluated using the unpaired $t$ test or the $\chi^{2}$ test. A threshold of $P<.05$ was considered significant. Results are presented as means \pm standard deviations (SDs).

\section{RESULTS}

Surgical outcomes for both groups (MPLP versus control) are (Table 2): blood loss (mL), 113.7 versus 87.9 ( $P=.45)$; operative time (minutes), 109.6 versuss $155.3(P=.0002)$; preoperative JOA score, 12.3 versus $10.8(P=.15)$; postoperative JOA score, 14.0 versus $12.8(P=.24)$; preoperative neck pain, 33.0 versus $31.3(P=.83)$; and postoperative neck pain, 1.8 versus $12.5(P=.005)$. Operative time and postoperative neck pain were significantly lower with MPLP compared to control $(P<.05)$. In terms of radiographic outcomes (Table 3): preoperative C2-7 angle $\left({ }^{\circ}\right), 14.0$ versus $19.5(P=.053)$;
Table 2. Surgical outcomes. Bold values indicate items with a significant difference between the two groups.

\begin{tabular}{lccl}
\hline Items & MPLP & Control & $\boldsymbol{P}$ Value \\
\hline Blood loss (mL) & $113.7 \pm 88.1$ & $87.9 \pm 76.7$ & .45 \\
Operative time (min) & $109.6 \pm 26.3$ & $155.3 \pm 25.7$ & $\mathbf{. 0 0 0 2}$ \\
Preoperative JOA score & $12.3 \pm 2.5$ & $10.8 \pm 2.4$ & .15 \\
Postoperative JOA score & $14.0 \pm 2.6$ & $12.8 \pm 2.6$ & .24 \\
Preoperative neck pain & $33.0 \pm 21.0$ & $31.3 \pm 9.9$ & .83 \\
Postoperative neck pain & $1.8 \pm 6.8$ & $12.5 \pm 13.9$ & $\mathbf{. 0 0 5}$ \\
\hline
\end{tabular}

Abbreviations: JOA, Japanese Orthopaedic Association; MPLP, myovascular preserving open-door laminoplasty.

postoperative $\mathrm{C} 2-7$ angle $\left({ }^{\circ}\right), 13.9$ versus $15.5(P=$ $.65)$; \% ROM, 87.0 versus $64.0(P=.025)$; implant back out, $0 / 29$ versus $0 / 17(P=.99)$; hinge union period (months), 6.0 versus $14.7(P=.0001)$; hinge nonunion, $1 / 64$ versus $0 / 44(P=.99)$; preoperative FI rate $(\%), 8.3$ versus $11.0(P=.278)$; and postoperative FI rate $(\%), 5.3$ versus $13.4(P=$ .0026). \% ROM was significantly increased in MPLP $(87 \%)$ compared to control $(64 \% ; P<.05)$. Hinge union period and postoperative FI rates were significantly lower with MPLP compared to control $(P<.05)$.

\section{DISCUSSION}

Laminoplasty for posterior spinal decompression has been used for treatment of CSM, which was devised with the intent of preserving the posterior structures of the cervical spine. Methods of laminoplasty are usually classified as unilateral open door (single door) ${ }^{1,3}$ or bilateral double door (French door). ${ }^{2}$

Postoperative problems, such as persistent axial pain, restriction of neck motion, and loss of lordotic curvature remain unsolved, although a variety of modifications have been developed for conventional cervical laminoplasty.

The deep extensor muscles, such as the semispinalis cervicis and multifidus muscles attached to the

Table 3. Evaluations of imaging studies. Bold values indicate items with a significant difference between the two groups.

\begin{tabular}{lccc}
\hline Items & MPLP & Control & $P$ Value \\
\hline Preoperative C2-7 angle $\left(^{\circ}\right)$ & $14.0 \pm 6.4$ & $19.5 \pm 7.5$ & .053 \\
Postoperative C2-7 angle $\left(^{\circ}\right)$ & $13.9 \pm 8.4$ & $15.5 \pm 8.7$ & .65 \\
\% ROM & $87.0 \pm 17.3$ & $64.0 \pm 37.6$ & $\mathbf{. 0 2 5}$ \\
Implant back out & $0 / 29$ & $0 / 17$ & .999 \\
Hinge union period (M) & $6.0 \pm 2.4$ & $14.7 \pm 9.0$ & $\mathbf{. 0 0 0 1}$ \\
Hinge nonunion & $1 / 64$ & $0 / 44$ & .9990 \\
$\begin{array}{l}\text { Preoperative fat infiltration } \\
\text { rate }(\%)\end{array}$ & $8.3 \pm 6.1$ & $11.0 \pm 5.9$ & .278 \\
$\begin{array}{l}\text { Postoperative fat infiltration } \\
\quad \text { rate }(\%)\end{array}$ & $5.3 \pm 4.9$ & $13.4 \pm 8.7$ & $\mathbf{. 0 0 2 6}$ \\
\end{tabular}

Abbreviation: MPLP, myovascular preserving open-door laminoplasty. 

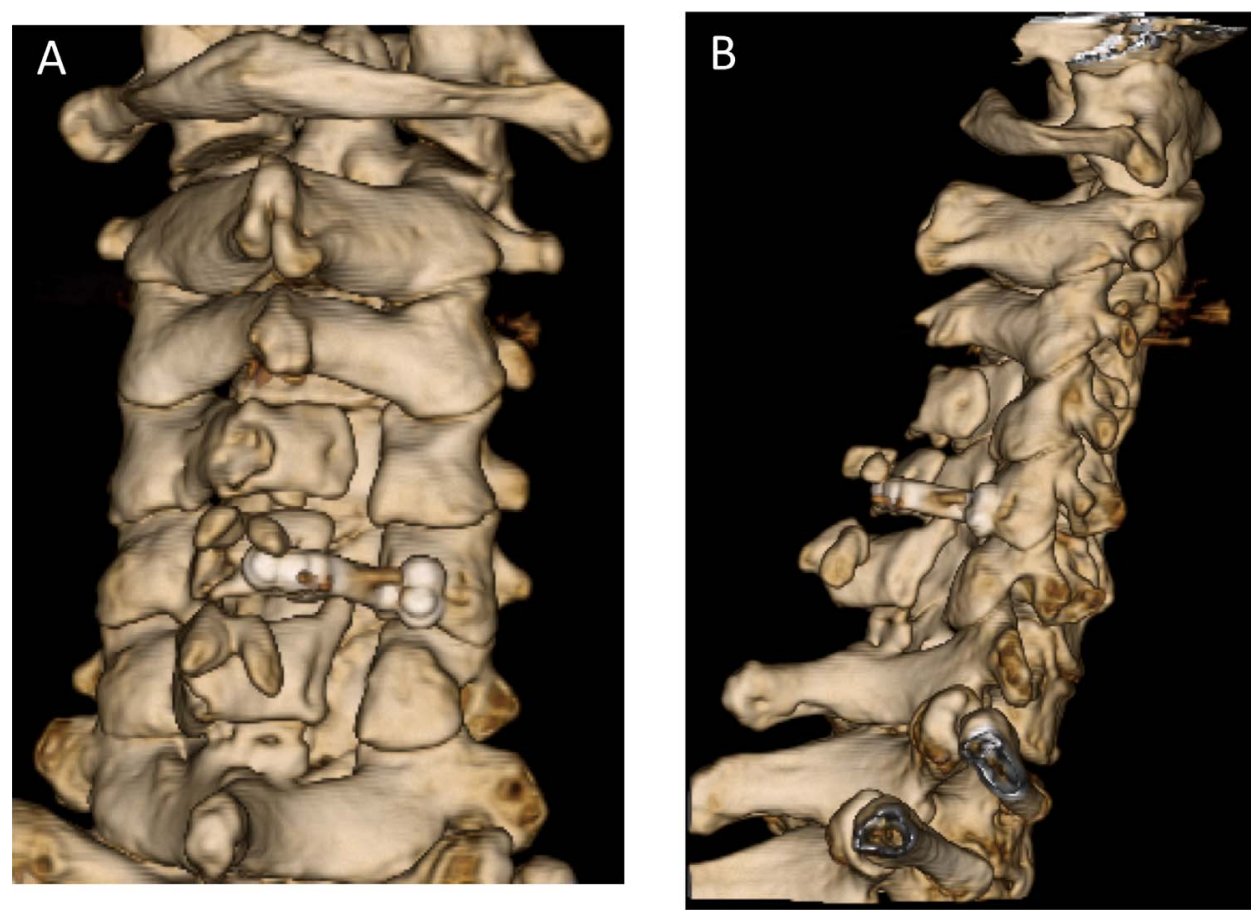

Figure 3. C4-6 myovascular preserving open-door laminoplasty postoperative three-dimensional computed tomography image. (A) posteroanteriorimage; (B) lateral view. A plate is placed on C5. Spinous processes that had been split also remained in the center and remained bone.

spinous processes, act as dynamic stabilizers of the cervical spine. Damage to the posterior extensor mechanism including the deep extensor muscles, such as the semispinalis cervicis and multifidus muscles, has been identified as a cause of these problems.

Shiraishi et $\mathrm{al}^{6-8}$ have described skip laminectomy to enlarge the spinal canal while preserving the semispinalis cervices and multifidus muscles. The spinous processes and laminae are split in the midline, and the muscles are left attached. By limiting excision of the posterior anatomic structures, skip laminectomy successfully prevented the aforementioned postoperative problems.

Kim et $\mathrm{al}^{9}$ developed myoarchitectonic spinolaminoplasty, in which the spinous processes are cut in the midline without damaging the posterior extensor muscles; then the lamina is drilled in the midline and finally lifted on the hinges bilaterally as a double door. It became possible to expand the spinal canal effectively while reconstructing and preserving the entire musculoskeletal elements of the posterior neck.

We developed MPLP. The posterior neck muscles can be preserved by an approach to the spinous processes entailing longitudinal split, and postoperative neck pain can be alleviated. Kim et al have reported that the origins and attachments of all muscle groups could be completely restored using double door laminoplasty, by suturing and fixing the spinous processes with the posterior cervical muscles attached to the fixed HA artificial spinous process implant on the lamina flap in the center. In our method, continuity with the vertebrae is not maintained because the enlarged vertebral arch is not sutured to the spinous processes with the posterior cervical muscles attached (Figure 3). Nevertheless, the postoperative FI rate is significantly less with MPLP than with the conventional method. The decrease in postoperative ROM is significantly restricted, and \% ROM was significantly increased in MPLP (87\%) compared to control $(64 \% ; P<.05)$. We believe cervical spine extension function is preserved more in MPLP than the conventional method.

The open-door laminoplasty was originally kept open with a suture technique. Nevertheless, the suture may be cut, broken, or stretched over time, which may result in the failure of fixation and closure of the laminae. Bone struts and ceramic blocks have also been used to open laminoplasty to keep an entire laminar arch. However, these spacers may be associated with complications, including loss of fixation and graft displacement, and premature laminoplasty closure because spacers are not rigidly fixed to bone. ${ }^{12}$ 
Ozawa et $\mathrm{al}^{13}$ developed the suture anchor fixation system, which enabled reliable and faster fixation of the HA spacers without creating a hole in the lateral mass in open-door laminoplasty.

The miniplate fixation system, first introduced by O'Brien et $\mathrm{al}^{4}$ in 1996, was designed to keep the lamina open in a stable manner by offering the laminae immediately rigid fixation.

Rhee et $\mathrm{al}^{14}$ demonstrated that plate-only laminoplasty provides stable reconstruction of an expanded laminar arch with no failure or premature closures. Seventy-seven percent of levels were healed at 6 months, and 93 percent at 12 months postoperatively. Lee et $\mathrm{al}^{15}$ reported that the hinge fusion rate after plate-only open-door laminoplasty was $84 \%$ at 12 months. We also were able to shorten the average time of hinge bone fusion by 4.9 months from 13.4 months using plates. Chen et $\mathrm{al}^{16}$ reported that minipalate fixation in cervical laminoplasty was a safe and effective procedure for a 5-year follow up.

Liu et $\mathrm{a}^{17}$ investigated 165 plates in 42 laminoplasty cases; $16 \%$ of plates and $5 \%$ of screws were detached, and it was reported that $80 \%$ of the detached screws were displaced most rostral-caudally. Screw back out at either end of the laminoplasty may be related to difficulty of screw insertion due to limited exposure and access. They recommended using a maximum number of screws (typically 2 for the lateral mass and 2 for the spinous process) at these levels to secure the plate to the bone. We skipped the plate without the rostral and caudal segments; nevertheless, there was no plate dislocation, and no hinge bone union failure was observed. We believe this method is useful and inexpensive. Based on this study, the plate seems to have good initial fixation; even though we installed a skipped plate, it seems there are no problems with hinge bone fusion.

Our study has several limitations. The first is that only a small number of subjects were investigated, requiring confirmation of our findings in a larger population. Second, this is a retrospective study with short follow up. Third, MPLPs were performed under different conditions using an approach that entailed a longitudinal splitting of the spinous processes and miniplates compared with a conventional laminoplasty using HA spacers. Fourth, we could not compare both groups with usual 4-level C3-6 laminoplasty. Finally, we did not perform MRI to analyze damage to the posterior cervical muscles. To verify the effectiveness of MPLP, it is necessary to increase the number of cases and to examine long-term clinical results.

\section{CONCLUSIONS}

We were able to perform MPLP using a plate. The posterior neck muscles could be preserved, and postoperative pain could be alleviated using an approach that entailed a longitudinal dissection of the spinous processes. Using a plate helped shorten the operating time, and this possibly shortened the time to hinge bone fusion as well.

\section{REFERENCES}

1. Hirabayashi K, Watanabe K, Wakano K, Suzuki N, Satomi K, Ishii Y. Expansive open-door laminoplasty for cervical spinal stenotic myelopathy. Spine (Phila Pa 1976). 1983;8(7):693-699.

2. Kurokawa R, Kim P. Cervical laminoplasty: the history and the future. Neurol Med Chir (Tokyo). 2015;55(7):529-539.

3. Itoh T, Tsuji H. Technical improvements and results of laminoplasty for compressive myelopathy in the cervical spine. Spine (Phila Pa 1976). 1985;10(8):729-736.

4. O'Brien MF, Peterson D, Casey AT, Crockard HA. A novel technique for laminoplasty augmentation of spinal canal area using titanium miniplate stabilization. A computerized morphometric analysis. Spine (Phila Pa 1976). 1996;21(4):474 483.

5. Park AE, Heller JG. Cervical laminoplasty: use of a novel titanium plate to maintain canal expansion - surgical technique. J Spinal Disord Tech. 2004;17(4):265-271. Review.

6. Shiraishi T. A new technique for exposure of the cervical spine laminae. Technical note. J Neurosurg. 2002;96(1 Suppl):122-126.

7. Shiraishi T, Fukuda K, Yato Y, Nakamura M, Ikegami T. Results of skip laminectomy-minimum 2-year follow-up study compared with open-door laminoplasty. Spine (Phila Pa 1976). 2003;28(24):2667-2672.

8. Shiraishi T, Kato M, Yato Y, et al. New techniques for exposure of posterior cervical spine through intermuscular planes and their surgical application. Spine (Phila Pa 1976). 2012;37(5):E286-E296.

9. Kim P, Murata H, Kurokawa R, Takaishi Y, Asakuno K, Kawamoto T. Myoarchitectonic spinolaminoplasty: efficacy in reconstituting the cervical musculature and preserving biomechanical function. J Neurosurg Spine. 2007;7(3):293-304.

10. Keller A, Gunderson R, Reikerås O, Brox JI. Reliability of computed tomography measurements of paraspinal muscle cross-sectional area and density in patients with chronic low back pain. Spine (Phila Pa 1976). 2003;28(13):1455-1460.

11. Lee SH, Park SW, Kim YB, Nam TK, Lee YS. The fatty degeneration of lumbar paraspinal muscles on computed tomography scan according to age and disc level. Spine $J$. 2017;17(1):81-87.

12. Kaito T, Hosono N, Makino T, Kaneko N, Namekata M, Fuji T. Postoperative displacement of hydroxyapatite 
spacers implanted during double-door laminoplasty. $J$ Neurosurg Spine. 2009;10(6):551-556.

13. Ozawa T, Toyone T, Shiboi R, et al. Modified open-door laminoplasty using a ceramic spacer and suture fixation for cervical myelopathy. Yonsei Med J. 2015;56(6):1651-1655.

14. Rhee JM, Register B, Hamasaki T, Franklin B. Plateonly open door laminoplasty maintains stable spinal canal expansion with high rates of hinge union and no plate failures. Spine (Phila Pa 1976). 2011;36(1):9-14.

15. Lee S, Chung CK, Kim CH. Risk factor analysis of hinge fusion failure after plate-only open-door laminoplasty. Global Spine J. 2015;5(1):9-16.

16. Chen H, Deng Y, Li T, Gong Q, Song Y, Liu H. Clinical and radiography results of mini-plate fixation compared to suture suspensory fixation in cervical laminoplasty: a five-year follow-up study. Clin Neurol Neurosurg. 2015;138:188-195.

17. Liu G, Buchowski JM, Riew KD. Screw back-out following "open-door" cervical laminoplasty: a review of 165 plates. Asian Spine J. 2015;9(6):849-854.

Disclosures and COI: The authors declare that they have no competing interests. We did not receive grants or external funding in support of our research or preparation of this manuscript. We did not receive payments or other benefits or a commitment or agreement to provide such benefits from any commercial entities. We declare that all protocols involving humans have been approved by the Shimoshizu National Hospital. Approval code: $\mathrm{H} 25^{\prime}-5$.

Corresponding Author: Yawara Eguchi, MD, PhD, Department of Orthopaedic Surgery, Center for Orthopaedic Science Medical Innovation, Graduated School of Medicine, Chiba University, 1-8-1 Inohana, Chuo-ku, Chiba, 260-8670, Japan. Phone: +81-43-226-2117; Fax: +81-43-2262116; Email: yawara_eguchi@yahoo.co.jp.

Published 28 August 2020

This manuscript is generously published free of charge by ISASS, the International Society for the Advancement of Spine Surgery. Copyright (C) 2020 ISASS. To see more or order reprints or permissions, see http://ijssurgery.com. 